\title{
Hairy Cell Leukemia Associated with A Bone Marrow Tuberculosis
}

Haouach K, Tazi I, Mahmal L and Harif M

Mohammed VI, University Hospital, Mohammed VI University Hospital, University Cadi Ayyad, Marrakech, Morocco.

*Corresponding author: Harif M, Sheikh Khalifa Hospital, Mohammed VI university of health science, Casablanca, Morocco, Tel: +212600021767; E-mail: mhmed.harif@gmail.com

Received date: Sep 04, 2015; Accepted date: Dec 10, 2015; Published date: Dec 16, 2015

Copyright: (c) 2015 Harif M. This is an open-access article distributed under the terms of the Creative Commons Attribution License, which permits unrestricted use, distribution, and reproduction in any medium, provided the original author and source are credited.

\begin{abstract}
Hairy cell leukemia is a chronic B-cell lymphoid leukemia characterized by pancytopenia, splenomegaly, myelofibrosis and the presence in peripheral blood, bone marrow and spleen of atypical lymphoid cells with a hairy aspect and a particular immunophenotypic profil. The association $\mathrm{HCL}$ and tuberculosis has been established, but only few cases have been reported.

We report a case of bone marrow tuberculosis with concomitant HCL. Initially, the histopathology of bone marrow led to a diagnosis of tuberculosis and myelofibrosis, without sufficient evidence for HCL. The anti-bacillary treatment was then started. Three months later, aspiration, biopsy and immunophenotyping of bone marrow were performed, a lymphoid population evoking hairy cells, was found. The patient received chemotherapy based pentostatin. The outcome was favorable.
\end{abstract}

Keywords: Hairy cell leukemia; Tuberculosis

\section{Introduction}

Hairy cell leukemia (HCL) is a chronic B-cell leukemia comprising, comprising only $2 \%$ of all leukemias and approximately $8 \%$ of all lymphoproliferative disorders [1]. It particularly predisposes to mycobacterial infections. Tuberculosis is a well-known event in HCL which was found in $8 \%$ of cases [2]. Tuberculosis may occur shortly after diagnosis of HCL or may be the mode of revelation [3].

We report a case of bone marrow tuberculosis with concomitant HCL, whose diagnosis was made by histopathology, morphological study and immunophenotyping of bone marrow, the patient received 12 course of pentostatin as well as anti-bacillary treatment during 9 month, the response to treatment was excellent.

\section{Case Presentation}

A 65 year old female was referred in mai 2014 with asthenia, anorexia, fevers and chills. On examination, overall condition was good, without indicative sign at examination. Her complete blood count showed a pancytopenia: neutropenia $0.41 \mathrm{G} / \mathrm{L}$, Anemia $10 \mathrm{~g} / \mathrm{dl}$ and thrombopenia $120.10 \mathrm{G} / \mathrm{l}$. The patient was then referred to hematology department.

The blood smears was normal, the bone marrow aspirate was poor with atypical lymphocytes, especially with extended cytoplasm and blurry edge. These few elements were not sufficient to guide diagnosis. Immunophenotyping on bone marrow showed $70 \%$ of T lymphocytes and only $6 \%$ of $\mathrm{B}$ cells with no evidence of monoclonality. Bone marrow biopsy showed signs of dysmyelopoiesis on megakaryocyte and erythrocyte lineages, stage 1 myelofibrosis in silver staining, epithelioid granulomas and giant cell with necrosis were also shown in Figure 1. The proposed diagnosis was tuberculosis associated with myelodysplasia. Intra-dermal tuberculin test was strongly positive. Search for mycobacterium tuberculosis was negative in sputum, bone marrow culture and broncho-alveolar lavage. CT scan of thorax and abdomen was normal. Bone marrow karyotype was also normal. Antituberculous therapy was then initiated. A clinical improvement was noted with weight gain. G-CSF therapy was also initiated with no improvement of hematologic parameters. Three months later, a new aspiration and biopsy of bone marrow were performed, myelofibrosis and lymphoid population evoking hairy cell were found (Figure 2).

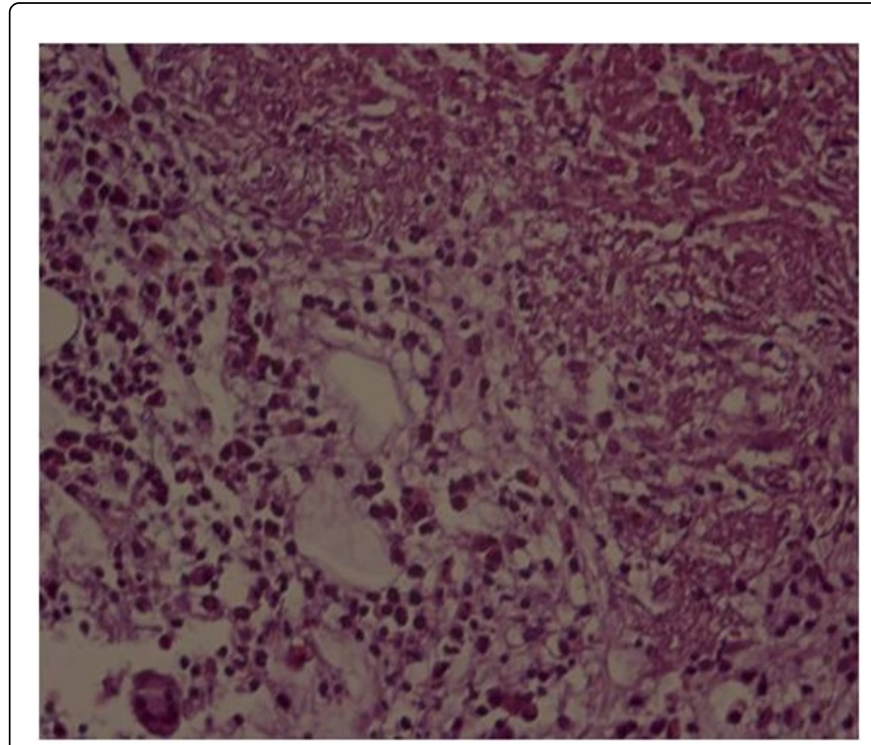

Figure 1: Biopsy of bone marrow showed epithelioid granulomas and giant cell with necrosis 


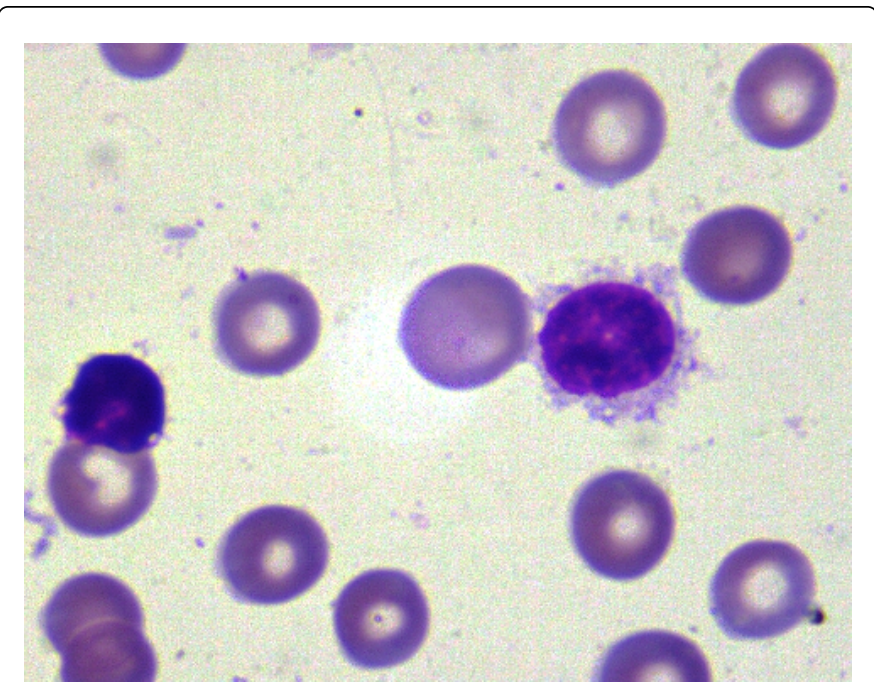

Figure 2: Aspiration of bone marrow showed atypical lymphoid cells with a hairy aspect

Previous bone marrow smears were reviewed, we found, a posteriori, "minor but sure" hairy cells infiltration. A new immunophenotyping of bone marrow was performed; CD103, CD 25, CD11c and CD123 were positif. Pentostatin was then started with 2 courses per month. Response to treatment was excellent: The pancytopenia quickly improved. The patient received 12 courses. Bone marrow biopsy, after six months, showed good recovery of hematopoiesis without hairy cells nor granuloma. The patient is currently in complete remission.

\section{Discussion}

The natural history of HCL includes frequent and severe infections; this is related to profound neutropenia and monocytopenia [4]. Damaj and al. demonstrated that the most important risk factor is the absolute lymphocyte count $(<1 \times 109 / \mathrm{L})$ at diagnosis [5].

The association between HCL and tuberculosis has been established. In a series of Rose and al, tuberculosis has been reported in $8 \%$ of case of HCL [6]. Tuberculosis may occur after treatment by chemotherapy, as it may be the mode of revelation [3]. The occurrence of tuberculosis during HCL is reported to be secondary to cellular immunity deficiency in particular the deficiency of monocyte-macrophage system [5].

In our patient the diagnosis of tuberculosis had preceded HCL.

Tuberculosis is in most cases disseminated and in particular hematopoietic diffusions are always present. It's characterized by scarse microbiological documentation [6] and

Histopathology is very interesting to confirm diagnosis [7].

In our patient, search for mycobacterium tuberculosis was negative in sputum, bone marrow culture and broncho-alveolar lavage. The Bone marrow biopsy showed epitheliod caseating granuloma.
Current diagnostic laboratory methods of HCL rely on morphology, immunohistochemistry (IHC) and flow cytometry [2]. Immunophenotyping is very useful in diagnosis of HCL. It differentiates HCL from its variants and other B cell malignancies, a scoring system of immunophenotypic markers has been proposed as ways to further improve phenotypic diagnostic accuracy [8]. According Abdel-Ghafar et al. IHC might be slightly more sensitive than flow cytometry in detecting bone marrow infiltration in HCL [9].

The immunophenotyping made in our patient showed only $6 \%$ of $B$ cells with no evidence of monoclonality, therefore the diagnosis of HCL has not been retained.

Our patient had received anti bacillary treatment. After three months, no improvement of blood counts led to the realization of bone marrow aspiration and biopsy, lymphoid population evoking hairy cell was found. An immunophenotyping was performed, the results were compatible with HCL.

The treatment of HCL by pentostatin or cladribine may cause lymphopenia with decreased $\mathrm{CD} 4$ rates and mono cytopenia, worsening immunosuppression and exposing to the risk of reactivation or resistance for tuberculosis treatment $[10,11]$. An early diagnosis and a prompt institution of antitubercular-therapy with respect of duration of treatment are important for succeeding in the treatment.

\section{References}

1. Grever MR, Blachly JS, Andritsos LA (2014) Hairy cell leukemia: Update on molecular profiling and therapeutic advances. Blood Reviews 28: 197-203.

2. Wanko SO, De Castro C (2006) Hairy Cell Leukemia: An elusive but Treatable Disease. The Oncologist 11: 780-789.

3. Troussard X (2000) Hairy cell leukemia. Encyclical Med Chir Hematology 8 .

4. Kraut E (2011) Infectious complications in hairy cell leukemia. Leuk Lymphoma Suppl 2: 50-2.

5. Damaj G, Kuhnowski F, Marolleau JP, Bauters F, Leleu X, et al. (2009) Risk factors for severe infection in patients with hairy cell leukemia: a long-term study of 73 patients. Eur J Haematol 83: 246-250.

6. Rose C, Auxenfants E, Noel MP, Mahieu M, Demory JL, et al. (1997) Tuberculosis, mycobacterium infection and hairy cell leukemia. Presse Med 26: 110-4.

7. Girardi K, Paviglianiti A, Cirillo M, Bianchi A, Gherardi G, et al. (2012) Tuberculous Meningoencephalitis in a Patient with Hairy Cell Leukemia in Complete Remission. J Clin Exp Hematop 52: 31-4.

8. Matutes E, Owusu-Ankomah K, Morilla R, , et al. (1994) The immunological profile of B-cell disorders and proposal of a scoring system for the diagnosis of CLL. Leukemia 8: 1640-1645.

9. Abdel-Ghafar A, El Telbany AS, Mahmoud HM, El-Sakhawy YN (2012) Immunophenotyping of chronic B-cell neoplasms: flow cytometry versus immunohistochemistry. Hematol Rep 4.

10. Ferrara G, Losi M, Fabbri LM, Migliori GB, Richeldi L, et al. (2009) Exploring the immune response against Mycobacterium tuberculosis for a better diagnosis of the infection. Arch Immunol Ther Exp 57: 425-433.

11. Cheson DB (1996) Perspectives on purine analogues. Hematol Cell Ther 38 Suppl 2: S109-116. 